\title{
Novas tendências no controle de incêndios florestais
}

\section{Ronaldo Viana Soares}

\section{INTRODUÇÃO}

Apesar do fogo ser um elemento natural, de fundamental importância para a formação e preservação de vários ecossistemas terrestres, como foi mostrado por exemplo na abertura dos jogos olímpicos de Sydney, incêndios florestais, em áreas modificadas pela ação antrópica, podem causar sérios danos ecológicos e materiais. Por este motivo e pela quantidade cada vez menor de áreas cobertas por florestas no mundo, existe uma grande preocupação com a ocorrência e propagação de incêndios florestais.

Como as florestas homogêneas plantadas são potencialmente mais susceptíveis aos incêndios, a tendência atual é adotar uma silvicultura preventiva, isto é, estabelecer técnicas de proteção contra o fogo desde a implantação dos povoamentos. Dentro deste conceito, o manejo do material combustível aparece como um fator importantíssimo na prevenção de grandes incêndios.

O estabelecimento de uma legislação eficiente e a aplicação de penalidades severas para os transgressores é outro ponto importante na prevenção dos incêndios. As diretrizes de manejo do fogo em áreas rurais pode ser uma importante ferramenta para disciplinar o uso do fogo e orientar a legislação específica sobre o assunto.

Os programas e campanhas de educação ambiental e conscientização da população para os efeitos daninhos do fogo são também muito importantes, principalmente para se reverter a tendência universalmente observada hoje em dia de aumento de incêndios causados por incendiários.

Finalmente, no que diz respeito ao combate daqueles incêndios que não se consegue prevenir, a utilização de novos produtos e equipamentos pode ajudar a limitar a expansão do fogo, minimizando a extensão das áreas queimadas e, conseqüentemente, os danos econômicos e ecológicos.

\section{SIL VICULTURA PREVENTIVA}

Silvicultura preventiva pode ser definida como o manejo das plantações florestais ou florestas nativas com o propósito de modificar a 
estrutura do material combustível disponível a fim de satisfazer os objetivos da proteção contra os incêndios, associando esta proteção ao melhoramento da produção e a qualidade do ambiente (HALTENHOFF 1998).

O objetivo da silvicultura preventiva é modificar a estrutura da massa florestal para dificultar a propagação do fogo. Este objetivo pode ser conseguido através da diversificação da massa florestal, da quebra da continuidade linear dos combustíveis no perímetro da mesma e ao longo de estradas, divisores e cursos de água, assim como conservando ou favorecendo a alternância das espécies. A diversificação da massa florestal deve ser feita respeitando-se a paisagem e as características da região, assim como os habitats da vida silvestre nela incluídos (VELEZ 1991).

O manejo do material combustível é portanto o ponto fundamental da silvicultura preventiva. Basicamente, segundo sua disposição no terreno, o combustível florestal possui uma continuidade horizontal e uma vertical. A continuidade horizontal é a distribuição espacial dos combustíveis sobre o terreno, enquanto a continuidade vertical é a ligação espacial da vegetação desde o solo até as copas das árvores.

Dentro do aspecto de controle de incêndios florestais, a quebra da continuidade horizontal, para evitar ou dificultar a propagação do fogo e a quebra da continuidade vertical, para evitar que o fogo suba nas árvores, iniciando incêndios de copa, são fatores muito importantes para facilitar as ações de combate e minimizar os danos causados às florestas.

\section{MANEJO DOS COMBUSTÍVEIS FLORESTAIS 1. REDUÇÃO DO MATERIAL COMBUSTÍVEL}

A redução consiste na eliminação, parcial ou total, dos combustíveis existentes em uma determinada área. Este tratamento está associado à utilização de queimas controladas, ao manejo silvopastoril, ao uso de herbicidas e à construção de aceiros.

Queima controlada: a queima controlada, embora ofereça certo risco e mesmo algum temor entre os administradores florestais, é o método mais prático, econômico e eficiente de redução do material combustível. No Brasil a queima é largamente usada na redução de resíduos, tanto agrícolas, depois da colheita, como florestais, depois da extração da madeira. O seu uso no interior de plantações ainda está em fase experimental, embora os resultados de trabalhos conduzidos por BATISTA (1995) e RIBEIRO (1997) tenham demonstrado a viabilidade e eficiência desta técnica em plantações de Pinus taeda e Eucalyptus viminalis.

Nos Estados Unidos, onde a técnica da queima controlada é largamente usada, principalmente na região sudeste, o Congresso Nacional 
recentemente concedeu um significativo aporte de recursos ao Serviço Florestal com a finalidade específica de aumentar o uso do fogo em áreas florestais para prevenir a ocorrência de grandes incêndios. Isto foi motivado pelo fato de nos últimos anos, apesar da diminuição do número de incêndios, ter sido constatado um aumento na superfície queimada, em função de incêndios de maior intensidade queimando em áreas de grande concentração de combustíveis.

A utilização da queima controlada na periferia de áreas florestais que fazem limite com zonas de alto risco, como por exemplo pastagens, estradas de ferro, estradas de rodagem e agricultura anual, formam faixas de proteção desprovidas de combustíveis que impedem a penetração e propagação de incêndios vindos de fora.

Como se trata de uma técnica que apresenta certo risco, já que se a prescrição for mal feita ou a queima mal conduzida o fogo pode fugir ao controle, causando um incêndio, ela somente deve ser empregada quando e onde necessária, sempre por pessoal capacitado, adotando-se todas as medidas de segurança cabíveis.

O uso do fogo controlado, aplicado segundo a legislação vigente, pode ser um elemento importante nos planos de prevenção de muitas áreas florestais, não apenas para a redução do material combustível, mas principalmente para influir na conscientização dos que usam o fogo em áreas rurais, pois está demonstrado que "proibir queimar" é uma política equivocada e ineficaz, enquanto que "ensinar a queimar", para que se faça bem feito, reduz o risco de danos e permite a obtenção dos benefícios que o fogo pode trazer aos agricultores, pecuaristas e florestais.

Manejo silvopastoril: consiste na utilização de gado bovino, caprino ou ovino, com o objetivo de que seja consumida a vegetação de menor porte, como gramíneas, ervas e arbustos. Em vários países, como por exemplo, Nova Zelândia, Espanha e Uruguai, esta técnica é adotada, pois além de reduzir o risco de incêndios ela gera um rendimento econômico adicional nas áreas florestais. Depois do trágico incêndio de interface urbano/florestal de Oakland, EUA, em 1991, o Departamento de Incêndios local contratou um rebanho de cerca de 200 cabras para pastorear em áreas limítrofes da cidade onde a vegetação oferecia riscos de propagar novos incêndios.

Uso de herbicidas: consiste na aplicação de produtos químicos inibidores do crescimento da vegetação. Pode ser usado nas margens de estradas de ferro ou rodagem e sob linhas de alta tensão. O seu uso entretanto tem sido limitado devido ao alto custo e aos efeitos ambientais negativos. Além disso, matando a vegetação existente, o produto provoca um aumento na quantidade de combustível seco, que por sua vez aumenta o risco de propagação do fogo. Portanto, o uso de herbicidas na verdade é uma faca de dois gumes e somente deve ser recomendado em condições especiais, mesmo 
assim adotando-se medidas posteriores para minimizar o efeito do aumento do combustível morto e seco.

Construcão de aceiros: aceiros são faixas relativamente largas, onde a continuidade da vegetação é interrompida ou modificada a fim de dificultar a propagação do fogo e facilitar o seu combate.

$\mathrm{O}$ aceiro é uma técnica universalmente usada, principalmente em reflorestamentos, para seccionar as áreas florestais, reduzindo o potencial de danos pelos incêndios. Como é muito difícil combater um incêndio no interior de uma plantação, principalmente de coníferas, o talhonamento sugere que se está disposto a sacrificar aquela área no caso da ocorrência de um incêndio. Por isto a rede interna de aceiros deve dividir a plantação em talhões preferencialmente de 20 a 50 ha e, para efeitos de proteção, nunca mais de 100 ha. Sob o aspecto da proteção, quanto menor o talhão, melhor; já sob a ótica econômica, quanto maior, melhor. As áreas sugeridas anteriormente se constituem num ponto de equilíbrio entre a proteção e a economia.

A largura dos aceiros varia de acordo com o tipo de floresta e com o grau de risco do local. Ela deverá estar relacionada com a altura da vegetação para evitar a passagem do fogo por radiação. O ideal é que a largura seja cerca de 2 vezes a altura das árvores, mas isto nem sempre é possível, pois representaria uma perda de área produtiva muito grande. De uma maneira geral, como raramente os incêndios começam no interior da floresta, os aceiros internos são mais estreitos (5 a 20 m) e os externos mais largos (20 a 100 m).

A localização dos aceiros externos depende da presença de fatores condicionantes do risco, principalmente presença humana e atividades agrícolas e pastoris. Por isto, sempre se deve dar atenção especial a áreas limítrofes a zonas habitadas, áreas adjacentes a culturas agrícolas e pastagens e áreas próximas a zonas de recreação ao ar livre. Por outro lado, estradas públicas, estradas de ferro, rios e afloramentos rochosos também atuam como aceiros e devem fazer parte dos planos de proteção.

\section{MODIFICAÇÃO ESTRUTURAL DOS COMBUSTÍVEIS}

A redução do risco de incêndio pode ser obtida também através da modificação da estrutura da vegetação no terreno, alterando sua continuidade vertical por meio de podas, horizontal por meio de desbastes, com a posterior compactação ou fragmentação dos resíduos.

A poda, principalmente em plantações de coníferas, mais susceptíveis aos incêndios de copa, evita ou dificulta a subida do fogo pela árvore. Em plantações manejadas para produção de madeira para serraria a poda é um tratamento silvicultural largamente utilizado para produzir madeira de alta qualidade. Na produção de madeira para celulose, no entanto, a poda não é necessária e não é feita pois a densidade da plantação é mais alta e a atividade seria antieconômica. Neste caso, recomenda-se podar algumas linhas (entre 5 e 
$10 \mathrm{~m}$ ) nas margens dos aceiros e retirar os resíduos, para diminuir o risco de incêndios e facilitar o combate.

Apesar de ser considerada uma técnica preventiva de incêndios, a poda adiciona uma apreciável quantidade de resíduos à superfície do solo, o que contribui para o aumento do risco de propagação do fogo. Por isto, logo após a operação de poda é recomendável a adoção tratamentos para a redução deste combustível, que pode ser a queima controlada ou a fragmentação do mesmo.

Os desbastes também, sob certas condições, podem ser considerados como redutores do risco de incêndios embora GRAHAM et al (1999) afirmem que os desbastes podem influir significativamente no comportamento do fogo, tanto aumentando como diminuindo a intensidade do incêndio e a severidade dos efeitos associados a ele. Segundo os mesmos autores, o desbaste por baixo ou o corte de cobertura ("shelterwood") reduzem o risco de incêndios de copa. Entretanto é necessário um tratamento dos combustíveis adicionados ao solo para reduzir o risco de incêndios superficiais.

A compactação dos combustíveis também diminui o risco de propagação dos incêndios ao reduzir a densidade básica dos mesmos; quanto menor a relação volume/peso maior a dificuldade de propagação do fogo. A compactação pode ser feita através da utilização de equipamento pesado, como grades acopladas a tratores. Este tratamento também acelera a decomposição natural dos resíduos mas é caro e, muitas vezes, inviável economicamente.

A fragmentação do combustível, que consiste em cortar o material em pedaços pequenos, é outra técnica de modificação estrutural do combustível que reduz o risco de propagação de incêndios florestais. A melhor maneira de fazer a fragmentação é através da utilização de picadores portáteis, que reduzem o material a cavacos. Os cavacos tanto podem ser deixados no terreno como usados para geração de energia em caldeiras de lenha. O uso de roçadeiras, manuais ou acopladas a tratores também produzem resultados semelhantes em certos combustíveis.

\section{REMOÇÃO DOS COMBUSTÍVEIS}

Considerando-se apenas o aspecto da proteção contra o fogo, a remoção dos combustíveis finos e médios das áreas florestais seria a maneira mais eficiente para se prevenir os incêndios florestais. Entretanto, a remoção total dos combustíveis não é recomendável ecologicamente nem viável economicamente.

A remoção dos combustíveis através da queima controlada, já discutida anteriormente, é uma das possibilidades. Às vezes, em locais de alto risco de incêndios, como margens de rodovias, pode-se remover os combustíveis de uma faixa da bordadura da floresta para um local de menor risco e queimá-lo. 
O material combustível de maior dimensão, como galhos e pedaços de tronco, pode ser removido por pessoas da comunidade florestal com a finalidade de utilizá-los posteriormente como fonte de energia, lenha ou carvão, para consumo próprio ou mesmo para a venda. Existem empresas florestais que estão adotando este sistema com ótimos resultados.

\section{DIVERSIFICAÇÃO DA MASSA FLORESTAL}

É recomendável, para efeito de proteção contra o fogo, diversificar a vegetação, evitando-se superfícies muito extensas cobertas por uma única espécie, principalmente se esta espécie for muito inflamável. O objetivo da diversificação é criar áreas de inflamabilidade diferenciada que alterem a intensidade de propagação do fogo facilitando seu combate.

Nos projetos de reflorestamento deve-se procurar intercalar espécies de diferentes inflamabilidades, como por exemplo, pinus ou araucária (mais inflamáveis) com eucalipto ou outra latifoliada (menos inflamáveis), obedecendo-se também os aspectos ecológicos e econômicos. As áreas de preservação permanente, compostas por florestas nativas, geralmente apresentam menor inflamabilidade do que as exóticas plantadas e por isto também podem ser usadas na diversificação da vegetação.

As faixas de espécies menos inflamáveis devem ser estabelecidas sempre que possível perpendicularmente à direção predominante do vento. As cortinas de segurança, estabelecidas com espécies menos inflamáveis nas margens de aceiros e estradas também apresentam o mesmo efeito de diversificação vegetal.

De qualquer modo, é sempre conveniente favorecer a mistura de espécies, ou pelo menos, garantir a presença de pequenos bosques de espécies diversas, que contribua para fracionar a continuidade de modelo de combustível.

\section{APLICAÇÃO DA LEGISLAÇÃO}

A legislação brasileira, no que se refere ao manejo do fogo $\mathrm{d}$ a floresta e as responsabilidades sobre o seu uso é atual e eficiente. A Portaria $\mathrm{N}^{\circ} 231$, de 08 de agosto de 1988, do então IBDF, institucionalizou o uso do fogo no país através da queima controlada e estabeleceu a necessidade de se solicitar permissão ao órgão ambiental competente para a utilização do fogo. O Decreto Presidencial No 97.635, de 10 de abril de 1989, instituiu o Sistema Nacional de Prevenção e Combate aos Incêndios Florestais (PREVFOGO) como responsável pela política de controle de incêndios no país. 
Mais recentemente, o Decreto Presidencial No 2.661, de 08 de julho de 1998 revogou o anterior e atualizou a legislação de manejo do fogo em áreas rurais, mantendo o PREVFOGO como responsável pelo ordenamento, monitoramento, prevenção e combate aos incêndios florestais, "cabendo-lhe ainda, desenvolver e difundir técnicas de manejo controlado do fogo, capacitar recursos humanos para difusão das respectivas técnicas e para conscientizar a população sobre os riscos do emprego inadequado do fogo". Em seu Art. $2^{\circ}$ ele estabelece que "Observadas as normas e condições estabelecidas por este Decreto é permitido o emprego do fogo em práticas agropastoris e florestais, mediante queima controlada". O Decreto mantém a exigência da solicitação para queima controlada ao órgão ambiental competente e apresenta outros artigos importantes, como por exemplo:

Art. 13. Os órgãos integrantes do SISNAMA poderão estabelecer escalonamento regional do processo de queima controlada, com base nas condições atmosféricas e na demanda de Autorização de Queima Controlada, para controle dos níveis de fumaça produzidos.

Art. 14. A autoridade ambiental competente poderá determinar a suspensão da Queima controlada da região ou município quando:

Art. 15. A Autorização de Queima Controlada será suspensa ou cancelada pela autoridade ambiental nos seguintes casos:

I - em que se registrarem risco de vida, danos ambientais ou condições meteorológicas desfavoráveis.

Art. 19. O IBAMA deverá exercer, de forma sistemática e permanente, o monitoramento do emprego do fogo e adotar medidas e procedimentos capazes de imprimir eficiência à prática da queima controlada e ao PREVFOGO.

Art. 22. Será permitida a utilização de Queima Controlada, para manejo do ecossistema e prevenção de incêndio, se este método estiver previsto no respectivo plano de manejo da unidade de conservação, pública ou privada, e da reserva legal.

Baseado nesta legislação, nas condições meteorológicas e nos pontos de calor detectados por satélite, o Instituto Estadual de Florestas de Minas Gerais está elaborando um calendário de queimas controladas para o estado, estabelecendo os períodos em que cada município pode efetuar queimas. Este é um passo importante para disciplinar o uso do fogo e prevenir os incêndios causados por queimas mal conduzidas e feitas em épocas inadequadas.

A Portaria $\mathrm{N}^{\circ}$ 94-N, de 09 de julho de 1998, do IBAMA, regulamenta o Decreto anteriormente citado e estabelece em se Art. $1^{\circ}$ que "Fica instituída a 
queima controlada como fator de produção e manejo em áreas de atividades agrícolas, pastoris ou florestais, assim como com finalidade de pesquisa científica e tecnológica, a ser executada em áreas com limites físicos preestabelecidos". A Portaria estabelece ainda que:

Art.11. A inobservância das disposições desta portaria sujeita os infratores às penalidades previstas na legislação vigente.

Art. 12. As penalidades incidirão sobre os autores, ou quem, de qualquer modo concorra com sua prática, de acordo com a legislação em vigor.

Parágrafo único - Para fins legais, tanto o responsável da queima controlada quanto os proprietários das áreas queimadas, serão igualmente responsabilizados.

Portanto, a legislação institucionaliza a queima controlada mas exige responsabilidade por parte de quem a pratica. Este é um aspecto importante e uma valiosa ferramenta para se prevenir os incêndios provocados por "Queimas para limpeza" que escapam ao controle, a principal causa de incêndios florestais no Brasil (SOARES 1995).

Entretanto, se por um lado a legislação é eficiente por outro lado a aplicação da legislação, tanto através da fiscalização como da atuação da justiça deixa muito a desejar. Os órgãos ambientais não têm estrutura de pessoal para fiscalizar e a difusão de técnicas e conscientização da população, previstas na legislação não têm sido implementadas. Além disso, nas poucas vezes que se faz uma autuação a justiça é lenta e geralmente privilegia empresas e proprietários infratores de alto poder aquisitivo.

\section{PROGRAMAS DE EDUCAÇÃO AMBIENTAL}

A técnica mais eficiente de prevenção do início dos incêndios de causas humanas, a médio e longo prazos, é a educação ambiental. Se as pessoas forem devidamente conscientizadas dos problemas e danos causados pelos incêndios, elas certamente serão mais cuidadosas no manuseio do fogo em áreas florestais.

A educação ambiental deve incluir obrigatoriamente o ensino de técnicas de queima e medidas de segurança para as pessoas do meio rural que utilizam o fogo como uma ferramenta no manejo de áreas agrícolas, silvicuturais e pastoris. Aqui, a utilização da legislação é um importante aliado na conscientização das pessoas, pois ela prevê a difusão de técnicas de queima controlada pelos órgãos competentes. Ensinar como fazer, ao invés de proibir, esta e a chave da questão.

Apesar de haver propostas, em alguns países, como Indonésia por exemplo, que têm sofrido bastante com problemas de incêndios ultimamente, 
ou de estados como São Paulo, que a institucionalizou, a proibição total do uso do fogo em áreas rurais é uma política equivocada e ineficiente, que leva ao agravamento do problema pois as pessoas ao invés de seguir a legislação, solicitando permissão para as queimas e adotando as medidas de segurança necessárias, simplesmente serão tentadas a fazê-las anonimamente.

Algumas empresas florestais têm feito excelentes campanhas de educação ambiental voltadas para o problema dos incêndios, com bons resultados. A criação de símbolos ilustrativos das campanhas, como o indiozinho Caiubi da Klabin, a ema Florema da Mannesmann e o tamanduá Labareda do IBAMA, representa uma excelente técnica de "marketing", pois facilita a memorização das mensagens através da visualização das figuras.

\section{AÇÕES DE COMBATE}

A prevenção dos incêndios, através das técnicas e táticas descritas anteriormente é muito importante, mas como a eliminação total da ocorrência de incêndios é uma meta inatingível, torna-se necessário estar preparado para combater os incêndios que não foram evitados.

A eficiência no combate é medida pela velocidade de extinção do incêndio, medida desde a ignição até o domínio do fogo. Atacar o fogo rapidamente é essencial para que o mesmo não se torne muito forte, pois não existe em nenhum país do mundo tecnologia capaz de combater um incêndio de alta intensidade. A história dos grandes e catastróficos incêndios ocorridos ao redor do mundo mostra que depois de certa intensidade somente a chuva, a neve, outras mudanças nas condições meteorológicas, ou o encontro de grandes obstáculos pode deter um incêndio de alta intensidade.

A eficiência no combate começa com um bom sistema de detecção, capaz de descobrir um incêndio no máximo até 15 minutos após o seu início, requer uma rápida rede de comunicação e mobilização do pessoal, passa pelo treinamento correto e freqüente das brigadas de primeiro combate e termina na disponibilidade de equipamentos e produtos adequados para a extinção do fogo.

$\mathrm{O}$ treinamento das brigadas de primeiro combate é um ponto importante para o sucesso da operação de supressão do fogo. Pessoas bem treinadas, tanto nas técnicas de combate como no manuseio das ferramentas manuais e outros equipamentos usados na extinção do fogo, têm maior chance de dominar um incêndio em menos tempo, reduzindo a área queimada e, conseqüentemente, os efeitos daninhos do fogo.

O desenvolvimento de novos produtos e equipamentos nas últimas décadas tornou possível maior rapidez e eficiência no combate aos incêndios. O desenvolvimento dos espumantes, que aumentam a eficiência da água em até 5 vezes, dependendo do tipo de equipamento utilizado, permitiu o uso de veículos 
menores, mais rápidos, que fazem o mesmo trabalho que os caminhões cisterna de grande capacidade de água. A tendência atual é usar caminhonetes com tanques de água transportados ou rebocados, de 400 a 10001 de água, que com a adição do espumante fazem o mesmo trabalho de um caminhão com 2000 a 5000 l. Além da maior rapidez, a utilização dos tanques menores não imobiliza os veículos apenas para combate aos incêndios, isto é, quando não existe risco de ocorrência de incêndios os veículos podem ser usados para outras atividades, reduzindo sensivelmente os custos operacionais da área de proteção florestal.

Outro produto recentemente desenvolvido é o extintor de explosão, também muito eficiente, que age de duas maneiras sobre o fogo, reduzindo o oxigênio da zona de combustão devido ao deslocamento de ar produzido pela explosão e espalhando retardante químico sobre a vegetação. Este produto é útil principalmente para deter uma frente de fogo de rápida propagação em locais de difícil acesso para os veículos de bombeamento de água, ou mesmo para as brigadas de primeiro combate. Ao contrário do espumante, considerado um retardante químico da combustão de curto prazo, o extintor de explosão usa o fosfato de amônia, considerado retardante de longa duração, pelo seu prolongado efeito inibidor sobre a ignição do combustível florestal.

\section{CONSIDERAÇÕES FINAIS}

Embora possam ocorrer incêndios intencionais em qualquer lugar da floresta, o normal é que eles se originem de atividades previsíveis, como a queima de pastagem, limpeza de terreno para agricultura ou reflorestamento, atividades de recreação, nas margens de estradas de ferro ou rodagem e na proximidades de zonas urbanas e acampamentos. As áreas de florestas próximas a essas atividades são as que maior atenção requerem e onde o manejo do combustível deve ser mais intenso.

Apesar da grande importância e da utilidade das técnicas de manejo de combustíveis florestais, elas não podem ser consideradas como substitutas, mas sim serem partes integrantes de um bom sistema de proteção contra incêndios florestais.

A tendência atual na área de controle de incêndios florestais é valorizar as técnicas da silvicultura preventiva e ao mesmo tempo utilizar a legislação e as campanhas de educação ambiental para conscientizar as pessoas sobre o problema dos incêndios florestais. No entanto, como a meta de "zero incêndio" em uma área florestal é inatingível e como por mais bem implantadas que sejam as técnicas da silvicultura preventiva, elas, apesar de reduzirem sensivelmente, não evitam totalmente a propagação do fogo, os empreendimentos florestais não podem prescindir de um eficiente sistema de combate aos incêndios, para minimizar os danos potenciais do fogo. 


\section{BIBLIOGRAFIA CITADA}

BATISTA, A.C. 1995. Avaliação da queima controlada em povoamentos de Pinus taeda L. no norte do Paraná. Curitiba, Universidade Federal do Paraná, Curso de Engenharia Florestal, Tese de Doutorado. 108 p.

GRAHAM, R.T.; HARVEY, A.E.; JAIN, T.B. \& TONN, J.R. 1999. The effects of thinning and similar stand treatments on fire behavior in western forests. USDA Forest Service, General Technical Report PNW-GTR. 27 p.

HALTENHOFF, H.D. 1998. Silvicultura preventiva. Santiago, Corporacion Nacional Forestal, Manual Técnico No 18.40 p.

RIBEIRO, G.A. 1997. Estudo do comportamento do fogo e de alguns efeitos da queima controlada em povoamentos de Eucalyptus viminalis Labill em Três Barras, Santa Catarina. Curitiba, Universidade Federal do Paraná, Curso de Pós-Graduação em Engenharia Florestal, Tese de Doutorado. 145 p.

SOARES, R.V. 1985. Incêndios Florestais: controle e uso do fogo. Curitiba, Fundação de Pesquisas Florestais do Paraná. 213 p.

SOARES, R.V. 1995. Ocorrência de incêndios em povoamentos florestais. Revista Floresta, 22 (1 e 2): 39-54.

VELEZ, R. 1991. Uso del fuego en selvicultura. Paris, Actas del $10^{\circ}$ Congreso Forestal Mundial, Vol. 2: 461-470. 